\title{
Hva tror legene en MR-undersøkelse koster?
}

\author{
Sammendrag \\ Bakgrunn. Legene har en portvakt- \\ rolle; de skal vurdere nytten og kostna- \\ dene ved ulike intervensjoner før de \\ gjennomfører tiltak. Dette betinger at \\ de har korrekt informasjon både om \\ nytte og kostnad. I denne artikkelen \\ unders $ø$ ker vi legers oppfatning om \\ kostnader forbundet med MR-under- \\ søkelse av et kne.
}

\begin{abstract}
Materiale og metode. Høsten 2006 sendte Legeforeningens forskningsinstitutt ut en spørreundersøkelse til 1400 representativt utvalgte norske leger. Følgende spørsmål ble stilt: «Hvor mye tror du en vanlig MR-undersøkelse av et kne koster til sammen (summen av klientenes egenandel og trygdens refusjon)?». For å sammenlikne svarene fra ulike undergrupper, brukte vi en uparet t-test. Videre brukte vi Pearsons korrelasjonskoeffisient for å se på sammenhengen mellom kostnadsvurderingen og andre variabler.
\end{abstract}

Resultater. Det var stor variasjon i legenes antakelser om kostnadene av MR-undersøkelsen. $57 \%$ av utvalget tok feil med over $50 \%$ i forhold til en faktisk pris på 1250 kroner. Den vanligste feilen er å overvurdere kostnadene (47\% oppga svar over 1875 kroner), mens $10 \%$ trodde kostnadene var under 625 kroner.

Fortolkning. Gjennom prioriteringsforskriften er legene pålagt å vurdere nytten mot kostnadene. Resultatene viser at det er rom for forbedring av kunnskapen om kostnadene. Uten korrekt informasjon om dette kan ikke legene ivareta sin portvaktfunksjon.

\section{Hans Olav Melberg}

hans.melberg@gmail.com

Helseøkonomisk forskningsprogram ved Universitetet i Oslo (HERO)

og

Avdeling for helseledelse og helseøkonomi (HELED)

Universitetet i Oslo

Postboks 1089 Blindern

0317 Oslo

\section{Berit Bringedal}

Legeforeningens forskningsinstitutt Oslo

Legene har en portvaktrolle (1), der de gjennom prioriteringsforskriften (2) er pålagt å veie nytten av ulike medisinske tiltak mot kostnadene. Dette fordrer korrekt kunnskap om både nytte og kostnader. Et eksempel på dette er bruken av MR-undersøkelser. Det har vært diskutert om slike undersøkelser benyttes for ofte (3-5). Man fant i en norsk studie at kostnadene per nyoppdaget menisk eller korsbåndsskade ved bruk av MR var omkring 7400 kroner (6). I denne studien så man på kostnaden $\mathrm{i}$ forhold til nytten målt $\mathrm{i}$ form av flere korrekte diagnoser. Det er imidlertid stor usikkerhet knyttet til hvor mange ekstra tilfeller man oppdager ved bruk av MR, og vi har derfor valgt å fokusere på kostnadene isolert. Fordi MR-teknologien var svært dyr da den ble innført, kan det feilaktig ha festet seg et inntrykk av at kostnadene fortsatt er svært høye og en mistanke om at undersøkelsen koster mer enn den smaker. Det er derfor interessant å undersøke forholdet mellom antatte og virkelige kostnader. Målet med denne artikkelen er å undersøke i hvor stor grad legene har korrekte oppfatninger om kostnadene knyttet til en MR-undersøkelse av knær.

\section{Materiale og metode}

Datagrunnlaget for denne studien er en spørreundersøkelse blant et representativt utvalg av 1400 norske leger som ble gjennomført høsten 2006 av Legeforeningens forskningsinstitutt. Utvalget tilhører et panel av norske leger som siden 1994 regelmessig er blitt spurt om ulike sider ved legevirksomhet og helsepolitikk (7). Spørsmålet om MR var åpent, slik at legene kunne fylle inn det beløpet de ønsket. Det lød slik: «Hvor mye tror du en vanlig MR-undersøkelse av et kne koster til sammen (summen av klientenes egenandel og trygdens refusjon)?» Dette spørsmålet inngikk i et knippe av spørsmål som handlet om kostnader, der vi blant annet også spurte: «Hvor mange milliarder kroner tror du staten bevilget til sykehusene i 2005? (1 000 kroner per innbygger $=4,6$ milliarder $) »$

Dataene fra spørreundersøkelsen ble analysert i SPSS versjon 16. For å sammenlikne svarene fra ulike undergrupper av leger, brukte vi en uparet t-test. Videre brukte vi Pearsons korrelasjonskoeffisient for å se på styrken i den lineære sammenhengen mellom kostnadsvurderingen og andre variabler.

Informasjon om takstene for en MR-undersøkelse (summen av NAV/RHF-takster og pasientens egenandel) ble innhentet fra Unilabs og Curato (tidligere Capio Røntgen og Sentrum Røntgeninstitutt). Prisene er regulert gjennom avtaler mellom bedriftene og myndighetene. Både egenandelen og refusjonstaksten påvirkes av sentrale retningslinjer, så prisene er tilnærmet lik mellom forskjellige røntgeninstitusjoner.

Forskjeller i svarkategorier for ulike grupper leger ble statistisk vurdert ved bruk av deskriptiv statistikk.

\section{Resultater}

789 av 1400 (56\%) forespurte leger svarte på kostnadsspørsmålene i spørreskjemaet. De virkelige takstene for en MR-undersøkelse (summen av NAV/RHF-takster og pasientens egenandel) er 1250 kroner.

Figur 1 viser hvordan legenes svar fordeler seg på ulike beløp. Svarene er ikke normalfordelt. Denne skjevheten gjør at gjennomsnittet påvirkes av noen få høye verdier, og medianen på 1500 kroner er nærmere den virkelige prisen enn gjennomsnittet på 2273 kroner. Samtidig er variasjonen i svarene svært stor. Et flertall (57\%) tar feil av kostnadene med mer enn $50 \%$ i forhold til den riktige summen på 1250 kroner. Den

\section{Hovedbudskap}

- Over halvparten av legene feilvurderer kostnadene ved en MR-undersøkelse, og flere tror at kostnadene er mer enn fire ganger større enn de faktisk er

- Leger har en portvaktrolle og må ha korrekt informasjon om nytte og kostnader når de skal vurdere medisinske tiltak

- Feilvurdering av kostnader kan føre til at nyttige tiltak ikke blir prioritert 
vanligste feilen er å overvurdere prisen: $47 \%$ oppga den til å være over 1875 kroner.

Tabell 1 viser en inndeling av kostnadsvurderingene blant ulike undergrupper av leger. Menn vurderer kostnaden til å være noe høyere enn det kvinner gjør. Videre er antatte kostnader synkende med legens alder. Leger generelt overvurderer kostnadene mer enn fastlegene. De som angir at de generelle sykehusutgiftene enten er lavere eller høyere enn reelt, tror tilsvarende om MR-kostnadene. Her er det små, men statistisk signifikante, forskjeller mellom gruppene.

\section{Diskusjon}

Resultatene fra spørreundersøkelsen viser at det er stor spredning i hva leger tror om kostnadene for en MR-unders $ø$ kelse av kne. Den vanligste feilen er å overvurdere omkostningene. I forhold til den virkelige prisen på 1250 kroner overvurderte $47 \%$ prisen med mer enn $50 \%$. Dette er et forsiktig anslag, fordi vårt kriterie om at man må ta feil med mer enn $50 \%$ for å anse det som en feilbedømning, er strengere enn det som brukes $i$ andre artikler. I den internasjonale litteraturen om legers prisvurderinger blir en feil på $25 \%$ ofte kategorisert som en feilvurdering (8). Grunnen til å bruke et strengere kriterium i vår studie er at det er vanskelig å si at en helt bestemt pris er korrekt. Vi har tatt utgangspunkt $i$ at en typisk MR-undersøkelse i året før vårt spørreskjema ble distribuert kostet 1250 kroner. Denne summen inkluderer egenandelen, refusjonene fra Rikstrygdeverket/NAV og andelen som betales av de regionale helseforetakene. Prisen avhenger imidlertid av flere forhold. For eksempel vil bruken av kontrast påvirke prisen. Det har også vært endringer over tid. Før 2001 hadde MR ingen egen takst, men NAV refunderte omkring 2000 kroner for en typisk MR-undersøkelse av et kne. I 2003 var den samlede prisen oppgitt til å være rundt 1500 kroner, mens den i 2005 var 1250 kroner. I perioden 2005-07 var det liten endring i NAV-satsen (31 kroner). Senere er satsene blitt betydelig redusert, slik at den samlede prisen for en MR-undersøkelse av et kne i 2008 lå på rundt 850 kroner.

Vi hadde en hypotese om at eldre leger overestimerte prisene mer enn unge. Dette fordi de ble introdusert for denne teknologien da den var mest kostbar. Antakelsen viste seg å være feil. Det var tvert imot slik at eldre leger hadde noe mer korrekt oppfatning enn de yngre.

Vi antok også at det kunne være en systematisk sammenheng mellom overvurdering av kostnader på ulike områder. Resultatene viste at de som tror at utgiftene til sykehusene generelt er høye også tror at prisen på MR er høy. Samtidig var forskjellen svært liten i kroner og øre ( 73 kroner). De store observerte forskjellene kan dermed i liten grad forklares med en form for tallblindhet, at man har en tendens til å oppgi store tall når man blir spurt om å gjøre et anslag.
$\mathrm{Vi}$ antok at fastleger ville ha mer korrekt kunnskap enn andre leger, ettersom de har en tydeligere portvaktrolle enn andre leger. Dette støttes av datamaterialet. Fastlegene er nærmere det korrekte beløpet enn andre leger. Om dette skyldes større bevissthet om rollen som portvakt, vet vi ikke.

Samtidig som noen av resultatene pekte i motsatt retning av det vi trodde, viser hovedresultatet viktigheten av å informere om kostnader. Når et flertall feilvurderer kostnadene med mer enn $50 \%$ og $12 \%$ tror at kostnadene er over 5000 kroner - mer enn fire ganger så store som de i virkeligheten er understreker dette ytterligere behovet for bedre informasjon. En så stor overestimering av kostnadene kan føre til at legen blir mer restriktiv med henvisning til MR enn det vedkommende bør være.

Kostnadsoversikten sier ikke noe om i hvor stor grad de legene som tror at MR koster mer enn det faktisk gjør, også er restriktive med bruken av MR. Tallene sier heller ikke noe om nytten av MR-undersøkelsen. Begge disse forholdene er viktige. Legens rolle som samfunnets portvakt innebærer ikke bare å begrense kostnader, men også å se nytten $\mathrm{i}$ forhold til kostnadene. Når det gjelder legers villighet til å ta hensyn til kostnadene, viser en studie at $68 \%$ av 151 allmennleger i Nord-Norge ofte eller noen ganger hadde valgt bort den beste behandlingen fordi den ville ha kostet samfunnet for mye (9). Denne studien er relativt liten og ble utført før fastlegereformen, noe som kan ha påvirket resultatene (10). Men også i internasjonal litteratur mener leger at de skal ta hensyn til samfunnets kostnader og at de gjør dette i praksis. En studie blant amerikanske leger viste at $88 \%$ var enige i at legen burde ta hensyn til kostnadseffekten når de skulle velge en behandling, og en tilsvarende andel ( $88 \%$ ) var uenige $i$ at man hadde en plikt til å tilby behandling uansett kostnader (11). En stor undersøkelse blant leger i Sveits viste det samme: $90 \%$ mente at det var en del av deres ansvar å begrense kostnadene (12). Dette tyder på at leger generelt tar hensyn til samfunnets kostnader og at ulike oppfatninger om kostnadene dermed kan få praktiske utslag.

Internasjonalt er det en interessant debatt om hvorvidt man bør innføre strengere regelbaserte kriterier for hvem som kan få MR ved kneskader. En oppsummering har vist at den såkalte «Ottawa knee rule» er kostnadseffektiv i den forstand at det reduserer utgiftene til radiologi (13). Denne undersøkelsen omhandler imidlertid kun knefrakturer. Man kan dermed ikke generalisere resultatene til å omfatte alle tilstander der MR kan være nyttig.

Ved tolking av våre resultater er det flere forhold man bør være oppmerksom på. Svarprosenten på 56 åpner for mulige skjevheter i utvalget. En sammenlikning av respondentene med hele legepopulasjonen viser imidlertid at utvalget ikke skiller seg fra populasjonen på sentrale variabler. $31 \% \mathrm{av}$ respondentene er kvinner, mens det var $33 \%$ kvinner blant praktiserende leger på undersøkelsestidspunktet. Aldersgjennomsnittet er 51 år, mot 49 år generelt. Fordelingen av ulike spesialiteter er også i hovedsak lik. Psykiatere er noe overrepresentert, mens samfunnsmedisinere er noe underrepresentert. Spørsmålet er en del av en generell un-

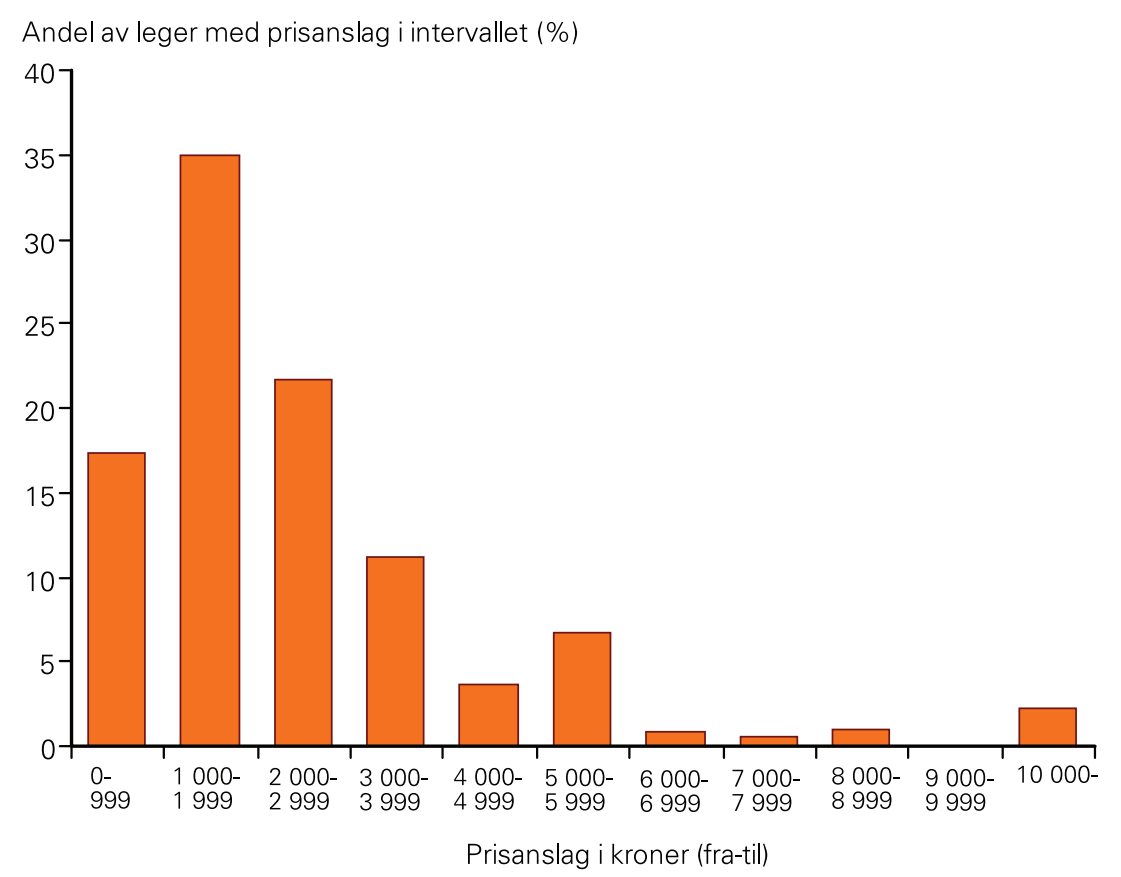

Figur 1 Prosentvis fordeling av legenes svar på hvor mye de tror en MR-undersøkelse av et kne koster. Korrekt kostnad er 1250 kroner 
Tabell 1 Antatte kostnader ved en MR-undersøkelse av et kne blant ulike undergrupper av leger

\begin{tabular}{|c|c|c|c|c|c|}
\hline & Gjennomsnitt & Median & Interkvartilbredde & Minimum-Maksimum & P-verdi ${ }^{1}$ \\
\hline Kjønn & & & & & 0,067 \\
\hline Kvinner ( $n=243$ ) & 2044 & 1500 & $(1000-2000)$ & $200-20000$ & \\
\hline Menn (n = 543) & 2364 & 1700 & $(1000-3000)$ & $100-20000$ & \\
\hline Alder & & & & & 0,006 \\
\hline under $40(n=201)$ & 2643 & 2000 & $(1000-3000)$ & $200-20000$ & \\
\hline $40-50(n=271)$ & 2235 & 1700 & $(1000-2500)$ & $100-15000$ & \\
\hline $50-60(n=231)$ & 2044 & 1500 & $(1000-2000)$ & $290-20000$ & \\
\hline over 60 ( $n=75)$ & 2073 & 1500 & $(1000-2750)$ & $400-10000$ & \\
\hline Hovedstilling & & & & & 0,001 \\
\hline Fastlege ( $n=203$ ) & 1890 & 1500 & $(1000-2000)$ & $100-12000$ & \\
\hline Andre $(n=573)$ & 2394 & 1500 & $(1000-3000)$ & $100-20000$ & \\
\hline Sykehusbevilgninger ${ }^{2}$ & & & & & 0,013 \\
\hline Lave $(n=301)$ & 2304 & 1500 & $(1000-3000)$ & $100-20000$ & \\
\hline Høye (n = 295) & 2376 & 2000 & $(1000-3000)$ & $250-20000$ & \\
\hline
\end{tabular}

dersøkelse om mange forhold. Det er dermed ikke slik at man bare har fătt med dem som har en spesiell interesse for tematikken kostnader og MR.

At prisen på MR-undersøkelse har variert over tid, er også et kompliserende forhold. Man ville trolig finne færre feil hvis man hadde undersøkt antakelser om utgiftene ved medisiner eller diagnostiske tester som har hatt en mer stabil kostnadsutvikling. Man bør derfor være forsiktig med å bruke resultatene fra denne undersøkelsen til å konkludere med at leger har lite presise oppfatninger om prisen på helsetjenester i sin alminnelighet. Om dette vet vi lite i Norge. Internasjonalt er det i undersøkelser påvist store variasjoner og avvik i legers oppfatninger av kostnadene for ulike legemidler og tester. En systematisk oversikt over disse studiene konkluderte med at det var en tendens til å underestimere kostnadene til dyre legemidler og å overvurdere kostnadene til de billige $(8,14)$. En slik feilvurdering kan få betydelige negative fordelingseffekter, for eksempel ved at svært nyttige tiltak ikke prioriteres på grunn av feiloppfatning om kostnad-nytte-forholdet.

Eksperimenter på området gir grunn til å tro at enkle tiltak innen informasjon og utdanning kan føre til forbedringer i kunnskap og praksis. Å gi legene en lommeguide med prisen på over 100 vanlige medikamenter er prøvd ut i USA (15). I Norge synes det enklere å videreutvikle de elektroniske oppslagsverktøyene for legemidler og å gi informasjon om ulike priser en mer fremtredende plass i disse systemene. Helsemyndighetene bør generelt legge større vekt på å gi beslutningstakerne oppdatert kunnskap om kostnad og nytte ved forskjellige behandlinger og tiltak. Dette kunne for eksempel samordnes med prioriteringsarbeidet som gjøres av fagmedisinske grupper og av prioriteringsrådet.

\section{Oppgitte interessekonflikter: Ingen}

\section{Litteratur}

1. Norges offentlige utredninger. Prioritering på ny. NOU 1997: 18. Oslo: Sosial- og helsedepartemen tet, 1997

2. FOR-2000-12-01 nr. 1208. Forskrift om prioritering av helsetjenester, rett til nødvendig helsehjelp fra spesialisthelsetjenesten, rett til behandling i utlandet og om dispensasjons- og klagenemnd.

3. Rapport fra Nasjonal strategigruppe for prioriteringer. Bodø: Nasjonal strategigruppe for prioriteringer, 2006.

4. Hanger MR. Kutt i bruk av MR kan spare 50 millioner. Dagens Medisin 10.11.2005. www. dagensmedisin.no/nyheter/2005/11/10/kutt-ibruk-av-mr-kan-spare/index xml (17.12 2009).

5. Hanger MR. Overdreven tro på MR. Dagens Medisin 12.1.2006. www.dagensmedisin.no/nyheter/ 2006/01/12/overdreven-tro-pa-mr/ [17.12.2009]

6. Frihagen F. Kvakstad R, Melhuus K et al. Bruk av MR-unders $ø$ kelser ved kneskader. Tidsskr Nor Lægeforen 2003; 123: $944-5$.
7. Legeforeningens forskningsinstitutt. Referansepanelet - vår viktigste datakilde. www.legeforeningen.no/ id/4714 (17.12.2009)

8. Allan GM, Lexchin J, Wiebe N. Physician awareness of drug cost: A systematic review. PLoS Med 2007. 4: 1486-96.

9. Arnesen T, Fredriksen S. Coping with obligations towards patient and society: an empirical study of attitudes and practice among Norwegian physicians. J Med Ethics 1995: 21: 158-61.

10. Carlsen B, Norheim OF. Introduction of the patient-list system in general practice. Changes in Norwegian physicians' perception of their gatekeeper role. Scand J Prim Health Care 2003. 21 : 209-13.

11. Ginsburg MI, Kravitz RL, Sandberg WA. A survey of physician attitudes and practices concerning costeffectiveness in patient care. West J Med 2000; 173: $390-4$

12. Bovier PA, Martin DP, Perneger TV. Cost-consciousness among Swiss doctors: a cross-sectional survey. BMC Health Serv Res 2005; 5: 72.

13. Bachmann LM, Haberzeth S, Steurer J et al. The accuracy of the Ottawa knee rule to rule out knee fractures: a systematic review. Ann Intern Med 2004; 140: $121-4$

14. Allan GM, Innes G. Family practice residents' awareness of medical care costs in British Columbia. Fam Med 2002; 34: 104-9

15. Korn LM, Reichert S, Simon T et al. Improving physicians' knowledge of the costs of common medications and willingness to consider costs when prescribing. J Gen Intern Med 2003; 18: $31-7$.

Manuskriptet ble mottatt 15.7. 2008 og godkjent 17.12. 2009. Medisinsk redaktør Michael Bretthauer. 